\title{
Association of telomere shortening with impaired glucose tolerance and diabetic macroangiopathy
}

\author{
Antonysunil Adaikalakoteswari, Muthuswamy Balasubramanyam*, \\ Radhakrishnan Ravikumar, Raj Deepa, Viswanathan Mohan \\ Department of Cell and Molecular biology, Madras Diabetes Research Foundation \& Dr.Mohan's Diabetes Specialities Centre, 4, \\ Conran Smith Road, Gopalapuram, Chennai 600 086, India
}

Received 6 April 2006; received in revised form 24 November 2006; accepted 2 December 2006

Available online 12 January 2007

\begin{abstract}
Objective: Shortening of telomere length has been reported in several conditions including Type 2 diabetes and atherosclerosis. The aims of this study were (1) to assess whether telomere shortening occurs at the stage of pre-diabetes, i.e., impaired glucose tolerance (IGT) and (2) whether telomere shortening was greater in Type 2 diabetic subjects with atherosclerotic plaques.

Methods: Subjects with impaired glucose tolerance (IGT) $(n=30)$, non-diabetic control subjects $(n=30)$, Type 2 diabetic patients without $(n=30)$ and with atherosclerotic plaques $(n=30)$ were selected from the Chennai Urban Rural Epidemiology Study (CURES), an ongoing epidemiological population-based study. Southern-blot analysis was used to determine mean terminal restriction fragment (TRF) length, a measure of average telomere size, in leukocyte DNA. Levels of thiobarbituric acid reactive substances (TBARS), protein carbonyl content (PCO) and high sensitive C-reactive protein (hs-CRP) were measured by standard methodologies. Carotid intima-media thickness (IMT) was assessed by high resolution B-mode ultrasonography.

Results: The mean $( \pm$ S.E.) TRF lengths were significantly lower in IGT subjects $(6.97 \pm 0.3 \mathrm{~kb} ; p=0.002)$ and lower still in Type 2 diabetic subjects without plaques $(6.21 \pm 0.2 ; p=0.0001)$ and lowest in Type 2 diabetic subjects with atherosclerotic plaques $(5.39 \pm 0.2 ; p=0.0001)$ when compared to control subjects $(8.7 \pm 0.5)$. In IGT subjects, TRF length was positively correlated to HDL cholesterol and negatively correlated to glycated hemoglobin $\left(\mathrm{HbA}_{1 \mathrm{c}}\right)$, TBARS, PCO, HOMA-IR and IMT. In multiple linear regression analysis, presence of diabetes, HDL cholesterol and increased TBARS levels appear as significant determinants of telomere shortening.

Conclusion: Telomere shortening is seen even at the stage of IGT. Among subjects with Type 2 diabetes, those with atherosclerotic plaques had greater shortening of telomere length compared to those without plaques.
\end{abstract}

(C) 2006 Elsevier Ireland Ltd. All rights reserved.

Keywords: Oxidative stress; Telomere shortening; Macroangiopathy; IGT

\section{Introduction}

Telomeres, composed of large arrays of short guanine-rich sequence, TTAGGG, are essential and dynamic regulators of cellular life span and chromosome integrity. The biology of telomeres has long been the focus of numerous investigations related to cancer. However, it is now realized that telomeres might also play primary or secondary roles in complex genetic disorders, including essential hypertension,

\footnotetext{
* Corresponding author. Tel.: +91 44 28359048; fax: +91 4428350935.

E-mail address: drbalu@mvdsc.org (M. Balasubramanyam).
}

atheroscelerosis and diabetes [1-3]. Telomere homeostasis is regulated through mutually reinforcing mechanisms, such as its precise protein composition, telomere length, and telomerase activity level. The probability of telomere shortening increases when one or more of these parameters is critically altered in response to factors such as increased systemic inflammation and oxidative stress $[1,3]$.

It is well known that increased risk for coronary artery disease (CAD) is seen not only in subjects with Type 2 diabetes but also at the stage of pre-diabetes or impaired glucose tolerance (IGT). This has also been shown for sub-clinical atheroclerosis as measured by carotid intima-medial thick- 
ness (IMT) [4]. We recently demonstrated the occurrence of telomere shortening in leukocytes from Asian Indian Type 2 diabetic patients [3] thus raising the possibility that telomere shortening might be a long-term risk marker of diabetes and macro-vascular complications. There are no studies to our knowledge that have looked at telomere shortening in prediabetes, i.e., at the stage of IGT. The present goal of this study was to therefore examine the telomere length in subjects with IGT. Additionally, we also studied Type 2 diabetic subjects with and without atherosclerotic plaques (carotid/femoral) to see whether telomere shortening was greater in Type 2 diabetic subjects with atherosclerosis.

\section{Subjects and methods}

\subsection{Sample selection}

Study subjects were recruited from the Chennai Urban Rural Epidemiology Study (CURES), the methodology of which has been published elsewhere [5]. Details such as age, sex and in diabetic subjects, duration of diabetes and other details of diabetic therapy were recorded and clinical examination was done in all subjects. Subjects with no known diabetes underwent oral glucose tolerance tests (OGTT) using $75 \mathrm{~g}$ of oral glucose load (dissolved in $250 \mathrm{ml}$ of water). Those who were confirmed by OGTT to have $2 \mathrm{~h}$ plasma glucose value $<7.8 \mathrm{mmol} / \mathrm{l}(140 \mathrm{mg} / \mathrm{dl})$ were categorized as normal glucose tolerance (NGT) and those with $2 \mathrm{~h}$ plasma glucose value $>7.8 \mathrm{mmol} / \mathrm{l}(140 \mathrm{mg} / \mathrm{dl})$ and $<11.1 \mathrm{mmol} / 1$ $(200 \mathrm{mg} / \mathrm{dl})$ were considered as impaired glucose tolerance (IGT). For the present study we randomly selected (using computer generated random numbers) diabetic subjects without $(n=30)$ and with atherosclerotic plaques $(n=30), 30$ subjects with IGT and 30 subjects with NGT. The study had a power of $80 \%$ to detect a statistically significant $(p<0.05)$ difference of $1.5 \mathrm{~kb}$ in TRF length between the study groups.

\subsection{Clinical and biochemical characterization}

Physical examination included height, weight, waist and hip measurements using standardized techniques. A fasting blood sample was taken and serum separated and stored at $-70{ }^{\circ} \mathrm{C}$ until the assays were performed. All biochemical analyses were done on Hitachi-912 Autoanalyser (Hitachi, Mannheim, Germany) using kits supplied by Roche Diagnostics (Mannheim, Germany) [5]. Glycated haemoglobin $\left(\mathrm{HbA}_{1 \mathrm{c}}\right)$ was estimated by high-pressure liquid chromatography using the Variant machine (Bio-Rad, Hercules, California, USA). Serum insulin concentration was estimated using Dako kits (Dako, Glostrup, Denmark). Insulin resistance was calculated using the Homeostasis Model Assessment (HOMA-IR) using the formula: fasting insulin $(\mu \mathrm{IU} / \mathrm{ml}) \times$ fasting glucose $(\mathrm{mmol} / \mathrm{l}) / 22.5$. To avoid the confounding effect of diabetic complications on telomeric shortening, the first group of diabetic subjects selected had no evidence of retinopathy (tested by retinal photography) or nephropathy ( $24 \mathrm{~h}$ protein excretion $<100 \mathrm{mg} /$ day and urinary albumin levels $<30 \mu \mathrm{g} / \mathrm{mg}$ creatinine). They also had no history of angina or myocardial infarction and had normal 12 lead resting ECGs. Hypertension was diagnosed if the subjects had been treated with antihypertensive drugs or had systolic blood pressure (SBP) $\geq 140 \mathrm{mmHg}$ or diastolic blood pressure $(\mathrm{DBP}) \geq 90 \mathrm{mmHg}$. Informed consent was obtained from all study subjects and the study was approved by the Institutional Ethics Committee.

\subsection{Assessment of intima-medial thickness (IMT)}

Intima-medial thickness (IMT) of the carotid arteries was determined using a high resolution B-mode ultrasonography system (logic 400 GE, MILWAUKEE, WI, USA) having an electrical linear higher frequency transducer $(7.5 \mathrm{MHz})$. The IMT was measured as the distance from the leading edge of the first echogenic line to the second echogenic line. The first echogenic line represents the lumen intimal interface and the second line is produced by the collagen-containing upper layer of the intimal adventitia. At each longitudinal projection, determinations of IMT were conducted at the site of greatest thickness and at two points $1 \mathrm{~cm}$ upstream and $1 \mathrm{~cm}$ downstream from the site of greatest thickness. Details of the methodology used have been described previously [6].

Imaging of the peripheral arteries of the lower limbs was done using high-resolution colour duplex ultrasound (LOGIC $400 \mathrm{MD}$ ). The lower limb vessels were studied with the extremities slightly externally rotated and using higher frequency transducers $(7.5 \mathrm{MHz})$ to obtain better image resolution. PVD (peripheral vascular disease) was diagnosed if the stenosis in the artery was greater than $50 \%$.

\subsection{DNA isolation and TRF length analysis}

Blood $(2 \mathrm{ml})$ was mixed with $5 \mathrm{ml}$ of chilled $2 \times$ lysis buffer $\left(10 \times-0.77 \mathrm{M} \mathrm{NH}_{4} \mathrm{Cl}, 0.46 \mathrm{M} \mathrm{K}_{2} \mathrm{HCO}_{3}\right)$, kept in ice for $20 \mathrm{~min}$ and centrifuged at $2000 \mathrm{rpm}$ for $10 \mathrm{~min}$. After a wash with the lysis buffer, the pellet (leukocytes) was collected and used for DNA isolation. DNA was isolated by digestion with proteinase- $\mathrm{K}$ and extraction with phenol/chloroform and was quantified spectrophotometrically. The DNA samples extracted from leukocytes were coded, and only after completion of the TRF measurement was the code broken for data analysis. Terminal restriction fragment (TRF) lengths were measured as previously described [3]. Briefly, equal amounts of DNA $(2 \mu \mathrm{g})$ were digested with restriction enzymes HinfI (20 U) and RsaI (20 U) (Roche Diagnostics, Mannheim, Germany) for $2 \mathrm{~h}$ at $37^{\circ} \mathrm{C}$. The TRF which determine the telomere lengths were separated by electrophoresis on $0.8 \%$ agarose gel denatured with $0.5 \mathrm{M}$ $\mathrm{NaOH} / 1.5 \mathrm{M} \mathrm{NaCl}$ and neutralized for $30 \mathrm{~min}$ in $0.5 \mathrm{M}$ Tris and $1.5 \mathrm{M} \mathrm{NaCl}$. The DNA was transferred overnight to a positively charged nylon membrane using capillary transfer. The membranes were then hybridized with telomeric 


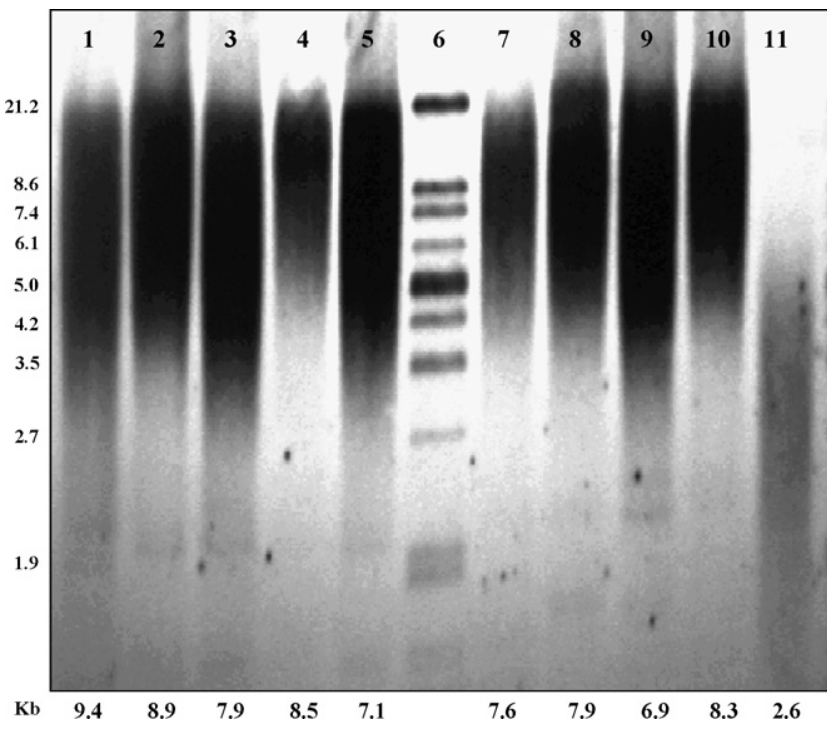

Fig. 1. An autoradiogram showing the lengths of the TRF of genomic DNA; lanes 1 and 11: reference samples (high $M_{\mathrm{W}}$ and low $M_{\mathrm{W}}$ ); lane 6: molecular weight marker (1.9-21.2 kb); other lanes: test samples from study subjects.

probe digoxigenin $3^{\prime}$ end labeled $5^{\prime}-(\text { CCCTAA })_{n}$ for $3 \mathrm{~h}$ in the hybridization solution. They were then washed at room temperature, three times in $2 \times$ saline sodium citrate (SSC), $0.1 \%$ SDS each for $15 \mathrm{~min}$ and once in $2 \times \mathrm{SSC}$ for $15 \mathrm{~min}$. The digoxigenin labeled probe was detected by digoxigenin luminescent detection procedure and exposed on X-ray film. The mean TRF length was determined using automated BIORAD Gel documentation software and calculated as follows: $\mathrm{TRF}=\sum \mathrm{ODi} /\left(\sum \mathrm{ODi} / \sum \mathrm{MWi}\right)$, where ODi is optical density at a given position in the lane and MWi is molecular weight at that position (Fig. 1). Reproducibility of our method was checked in blood samples taken twice from the same subjects on two different occasions and validated as described earlier [4]. The inter-assay coefficient of variation was $<3 \%$ and blot to blot variability was $<7 \%$.

\subsection{CRP measurement}

The plasma concentrations of hs-CRP were measured by a highly sensitive nephelometric assay using a monoclonal antibody to CRP coated on polystyrene beads (Dade Behring, Marburg, Germany). The intra- and inter-assay coefficient of variation for hs-CRP were 4.2 and $6.8 \%$, respectively, and the lower detection limit was $0.17 \mathrm{mg} / \mathrm{l}$.

\subsection{Lipid peroxidation}

Plasma level of malonodialdehyde (MDA), a marker of lipid peroxidation was measured by TBARS (thiobarbituric acid reactive substances) by fluorescence methodology [3]. Absolute MDA (malonodialdehyde) levels were calculated using the regression parameters obtained using various concentration $(0.25-5.0 \mathrm{nM})$ of the standard, $1,1^{\prime}, 3,3^{\prime},-$ tetramethoxypropane. Inter- and intra-assay coefficient of variation were $<5$ and $10 \%$, respectively.

\subsection{Protein carbonyls}

Carbonyl content was evaluated by the 2,4-dinitrophenylhydrazine (DNPH) assay [7]. Blanks were run with $2 \mathrm{M}$ $\mathrm{HCl}$ alone instead of DNPH reagent. All measurements were carried out in duplicate. The intra- and inter-assay coefficients of variation were 2.2 and $2.8 \%$, respectively. Carbonyl content was expressed in nanomoles per milligram of protein, using a molar absorption coefficient of $22,000 \mathrm{M}^{-1} \mathrm{~cm}^{-1}$. Protein concentration was determined using a standard curve with bovine serum albumin (BSA: $0.25-5.0 \mathrm{mg} / \mathrm{ml}$ ) dissolved in guanidine hydrochloride and read at $280 \mathrm{~nm}$.

\subsubsection{Statistical analysis}

Comparisons between groups were performed using unpaired Student's $t$-test and one-way ANOVA. The criterion for significance is $p<0.05$. Pearson correlation analysis was done between variables. Risk variables that had significant association with TRF on univariate regression, were included as independent variables in multiple linear regression analysis. Care was taken to avoid inter-correlated variables in the regression equation. All analysis was done using Windows based SPSS statistical package (Version 10.0, Chicago, IL).

\section{Results}

Table 1 summarizes the characteristics of the study subjects. None of the diabetic patients had ketonuria or any history of diabetic ketosis at any time and all were treated with oral agents sulphonylurea (glipizide or glibenclamide) and/or metformin. Hence they were all diagnosed to have Type 2 diabetes. Whereas 20 of the diabetic subjects without atherosclerotic plaques and nine with plaques were only on glucose-lowering agents, 10 diabetic patients without plaques and 21 with plaques were on ACE inhibitors and/or statin or aspirin therapy, in addition to glucose-lowering agents. Diabetic patients with or without atherosclerotic plaques had significantly higher fasting plasma glucose, $\mathrm{HbA}_{1 \mathrm{c}}$, triglycerides and HOMA-IR compared to control subjects and impaired glucose tolerance subjects.

When compared to control subjects $(8.7 \pm 0.5 \mathrm{~kb})$, the mean $( \pm$ S.E.) TRF lengths were significantly lower in IGT subjects $(6.97 \pm 0.3 \mathrm{~kb} ; p=0.002)$ and diabetic subjects without atherosclerotic plaques $(6.21 \pm 0.2 \mathrm{~kb} ; p=0.0001)$ and still lower in diabetic subjects with atherosclerotic plaques $(5.39 \pm 0.2 \mathrm{~kb} ; p=0.0001)$ (Fig. 2). Age-adjusted telomere lengths were significantly $(p=0.004)$ shorter in men versus women in both control $(7.36 \pm 0.5 \mathrm{~kb}$ versus $10.52 \pm 0.9 \mathrm{~kb})$ and IGT $(6.57 \pm 0.2 \mathrm{~kb}$ versus $8.74 \pm 0.7 \mathrm{~kb})$ subjects. There was no significant gender difference $(6.1 \pm 0.5 \mathrm{~kb}$ versus $6.88 \pm 0.2 \mathrm{~kb}$ ) in TFR lengths in diabetic subjects without atherosclerotic plaques. However, in those diabetics with 
Table 1

Clinical characteristics of the study subjects

\begin{tabular}{|c|c|c|c|c|}
\hline Parameters & Control $(n=30)$ & $\begin{array}{l}\text { Impaired glucose } \\
\text { tolerance }(n=30)\end{array}$ & $\begin{array}{l}\text { Type } 2 \text { diabetes without } \\
\text { plaques }(n=30)\end{array}$ & $\begin{array}{l}\text { Type } 2 \text { diabetes with } \\
\text { plaques }(n=30)\end{array}$ \\
\hline Age (years) & $49 \pm 8$ & $47 \pm 9$ & $49 \pm 7$ & $63 \pm 8^{*}, \S, 9$ \\
\hline Duration of diabetes (years) & - & - & $3 \pm 2$ & $13 \pm 6$ \\
\hline Fasting plasma glucose (mmol/l) & $4.6 \pm 0.4$ & $5.4 \pm 0.7$ & $8.6 \pm 3.7^{*}, \S$ & $8.7 \pm 0.4^{*}, \S$ \\
\hline Glycated hemoglobin $(\%)$ & $5.5 \pm 0.6$ & $6.3 \pm 1.1$ & $9.4 \pm 2.7^{*}, \S$ & $8.6 \pm 2.1^{*}, \S$ \\
\hline Systolic blood pressure (mmHg) & $117 \pm 11$ & $124 \pm 16^{*}$ & $124 \pm 24$ & $135 \pm 22^{*}, \S$ \\
\hline Diastolic blood pressure $(\mathrm{mmHg})$ & $74 \pm 9$ & $80 \pm 7^{*}$ & $78 \pm 13$ & $79 \pm 11^{*}$ \\
\hline Body mass index $\left(\mathrm{kg} / \mathrm{m}^{2}\right)$ & $23 \pm 3$ & $26 \pm 3^{*}$ & $25 \pm 4^{*}$ & $26 \pm 4^{*}$ \\
\hline Serum cholesterol (mmol/l) & $4.6 \pm 0.9$ & $4.8 \pm 1.0$ & $5.1 \pm 1.1$ & $4.8 \pm 1.2$ \\
\hline Serum triglycerides $(\mathrm{mmol} / \mathrm{l})$ & $1.5 \pm 0.7$ & $1.8 \pm 0.6$ & $2.4 \pm 1.2$ & $2.3 \pm 1.1$ \\
\hline Serum HDL cholesterol ( $\mathrm{mmol} / \mathrm{l})$ & $1.1 \pm 0.3$ & $1.0 \pm 0.2$ & $1.1 \pm 0.3$ & $1.0 \pm 0.2$ \\
\hline Serum LDL cholesterol (mmol/1) & $2.9 \pm 0.8$ & $3.1 \pm 0.8$ & $3.1 \pm 1.0$ & $3.3 \pm 0.9$ \\
\hline HOMA-IR & $1.8 \pm 1.1$ & $2.8 \pm 1.4$ & $4.2 \pm 2.9^{*}, \S$ & $4.8 \pm 2.6^{*}, \S$ \\
\hline IMT (mm) & $0.74 \pm 0.1$ & $0.77 \pm 0.2$ & $0.8 \pm 0.2$ & $1.06 \pm 0.2^{*}, \S \rrbracket$ \\
\hline TBARS $(\mathrm{nm} / \mathrm{ml})$ & $6.4 \pm 2.5$ & $10.6 \pm 5.7^{*}$ & $12.2 \pm 6.7^{*}$ & $16.8 \pm 6.4^{*}, \S \rrbracket$ \\
\hline PCO (nm/mg protein) & $0.6 \pm 0.2$ & $0.8 \pm 0.2^{*}$ & $1.0 \pm 0.3^{*}, \S$ & $1.7 \pm 0.5^{*, \S, \emptyset ~}$ \\
\hline C-reactive protein $(\mathrm{mg} / \mathrm{l})$ & $1.4 \pm 1.1$ & $3.0 \pm 2.5^{*}$ & $3.9 \pm 3.1^{*}$ & $5.4 \pm 3.9^{*}, \S$ \\
\hline
\end{tabular}

Values are expressed as mean \pm S.D.; ${ }^{*} p<0.05$ compared to controls; ${ }^{\S} p<0.05$ compared to Impaired glucose tolerance; ${ }^{\uparrow} p<0.05$ compared to Type 2 diabetes without atherosclerotic plaques.

atherosclerotic plaques, men had significantly shortened telomeres than women $(4.14 \pm 0.3 \mathrm{~kb}$ versus $5.2 \pm 0.2 \mathrm{~kb}$, $p=0.02)$.

Compared to control subjects $(6.4 \pm 0.5 \mathrm{nM} / \mathrm{ml})$, the levels of TBARS were significantly $(p<0.05)$ higher in IGT subjects $(10.6 \pm 1.0)$ and in Type 2 diabetic patients without $(12.2 \pm 1.2)$ and with atherosclerotic plaques $(16.8 \pm 1.2)$. PCO levels were progressively and significantly $(p<0.05)$ increased in IGT subjects $(0.79 \pm 0.04 \mathrm{nM} / \mathrm{mg}$ protein) and in Type 2 diabetic patients without $(0.97 \pm 0.05)$ and with atherosclerotic plaques $(1.67 \pm 0.09)$ compared to control subjects $(0.58 \pm 0.03)$. IGT subjects $(3.0 \pm 0.5 \mathrm{mg} / \mathrm{l})$ and diabetics without $(3.9 \pm 0.6)$ and with atherosclerotic plaques $(5.4 \pm 0.7)$ also exhibited significantly $(p<0.05)$ higher levels of CRP, compared to control subjects $(1.4 \pm 0.2)$ (Table 1$)$.

To determine whether ACE inhibitor/statin/aspirin therapies interfere with biomarker levels, we analyzed the data

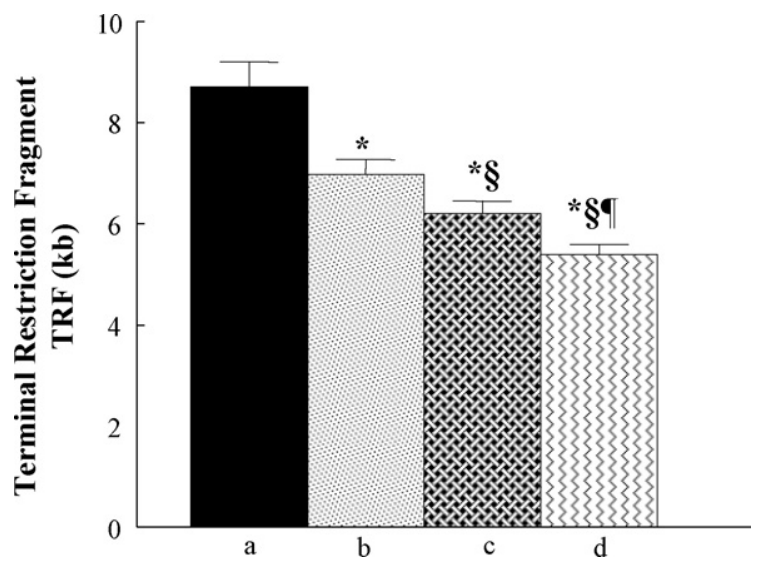

Fig. 2. Mean ( \pm S.E.) telomere lengths of (a) control subjects $(8.7 \pm 0.5 \mathrm{~kb})$; (b) IGT subjects $(6.97 \pm 0.3 \mathrm{~kb})$; (c) diabetic subjects without $(6.21 \pm 0.2 \mathrm{~kb})$; (d) with atherosclerotic plaques $(5.39 \pm 0.2 \mathrm{~kb})$. related to TRF length, TBARS, PCO, and CRP levels in diabetic patients $(n=60)$ by dividing them into two groups: those taking only glucose-lowering agents (group A, $n=29$ ) and those taking glucose-lowering agents along with ACE inhibitor/statin/aspirin (group B, $n=31$ ). No significant differences in estimated TRF length, TBARS, PCO and CRP levels were observed (data not shown) and this apparent lack of change supports the notion that the associated therapy may not directly alter biomarker levels in diabetic patients.

Correlation analysis showed that in control subjects the age-adjusted TRF length correlated positively with HDL and negatively with TBARS and PCO levels, IMT and HOMAIR (Table 2). Similar correlations were seen in IGT subjects with an additional negative association between TRF length and $\mathrm{HbA}_{1 \mathrm{c}}$ levels. In patients with diabetes, TRF length was positively correlated to HDL and negatively correlated to diabetes duration, $\mathrm{HbA}_{1 \mathrm{c}}$, BMI, triglycerides, TBARS, PCO, CRP levels, insulin resistance and IMT.

When age, sex, smoking, presence of diabetes, HbAlc, TBARS, PCO, CRP and HDL cholesterol were included as potential independent variables in the stepwise regression analysis, presence of diabetes $(\beta=-0.696 ; p=0.0001), \mathrm{HDL}$ cholesterol $(\beta=0.067 ; p=0.0001)$ and TBARS $(\beta=-0.092$; $p=0.001)$ independently predicted the TRF length (Table 3 ).

\section{Discussion}

This study presents three important observations. First, in Asian Indians who are considered more insulin resistant [8] and have a higher risk of developing Type 2 diabetes, there is an association of telomere shortening with impaired glucose tolerance. To the best of our knowledge this is the first study to show telomere shortening in subjects with IGT. Secondly, Type 2 diabetic subjects with atherosclerotic plaques 
Table 2

Correlation of age-adjusted TRF with biochemical parameters

\begin{tabular}{|c|c|c|c|c|c|c|}
\hline \multirow[t]{2}{*}{ Parameters } & \multicolumn{2}{|c|}{ Control subjects $(n=30)$} & \multicolumn{2}{|c|}{$\begin{array}{l}\text { Impaired glucose tolerance } \\
\text { subjects }(n=30)\end{array}$} & \multicolumn{2}{|c|}{$\begin{array}{l}\text { Type } 2 \text { diabetes patients with and } \\
\text { without plaques }(n=60)\end{array}$} \\
\hline & $r$ & $p$ & $r$ & $p$ & $r$ & $p$ \\
\hline Duration of diabetes & - & - & - & - & -0.63 & 0.0001 \\
\hline Glycated hemoglobin & NS & NS & -0.44 & 0.02 & -0.31 & 0.02 \\
\hline Body mass index & NS & NS & NS & NS & -0.37 & 0.004 \\
\hline Serum HDL cholesterol & 0.44 & 0.01 & 0.37 & 0.04 & 0.40 & 0.002 \\
\hline Triglycerides & NS & NS & NS & NS & -0.27 & 0.04 \\
\hline HOMA-IR & -0.42 & 0.02 & -0.38 & 0.04 & -0.49 & 0.0001 \\
\hline Intima-media thickness & -0.49 & 0.006 & -0.43 & 0.02 & -0.63 & 0.0001 \\
\hline TBARS & -0.42 & 0.02 & -0.36 & 0.05 & -0.49 & 0.0001 \\
\hline Protein carbonyls & -0.44 & 0.01 & -0.46 & 0.01 & -0.63 & 0.0001 \\
\hline C-reactive protein & NS & NS & NS & NS & -0.49 & 0.0001 \\
\hline
\end{tabular}

had significantly shorter telomeres compared to diabetic subjects without atherosclerotic plaques. Thirdly, shortening of telomeres was associated with increased markers of systemic inflammation and oxidative stress.

Telomere shortening has recently been shown to occur in many age-related diseases $[1,3,9]$. The association between shortened telomeres and IGT observed in this study is of particular interest. An increased predisposition to diabetes and coronary artery disease (CAD) among Asian Indians has long been recognized and claimed to stem in most part from IGT [10]. The higher rates of CAD and Type 2 diabetes among Indians are also often not explained by traditional risk factors. Therefore, telomere shortening may represent a non-traditional risk factor and long-term biomarker to be associated with IGT and in the natural history of diabetes and cardiovascular diseases. One problem with this claim is that increased leukocyte turnover in 'inflammatory' IGT subjects might have produced a confounding effect, i.e., more cell divisions in leukocyte populations could have contributed to telomere shortening. However, this may not be wholly true, as there was no correlation between CRP levels and telomere length in IGT subjects, and in a logistic regression analysis, CRP levels did not affected the association of IGT with telomere shortening. Similarly, markers of inflammation have not affected the association of shorter telomeres with risk of myocardial infarction [11]. Therefore, the shorter telomeres observed in WBCs from IGT subjects may not reflect simply an epiphenomenon. Referring to the recent literature, it appears that telomere attrition is strongly correlated with insulin resistance (IR) [12,13]. Moreover, it was inferred from the Framingham Heart Study that shorter leuko-

Table 3

Multivariate regression analysis for the association of telomere restriction fragment (TRF) length in study subjects

\begin{tabular}{llll}
\hline Model TRF & \multicolumn{2}{l}{ Unstandardized coefficients } \\
\cline { 2 - 4 } & \multicolumn{1}{c}{$\beta$} & Standard error & Significance \\
\hline Diabetic group & -0.696 & 0.160 & 0.0001 \\
HDL & 0.067 & 0.016 & 0.0001 \\
TBARS & -0.092 & 0.028 & 0.001 \\
\hline
\end{tabular}

cyte telomere length in hypertensives is largely due to insulin resistance [14]. There is increasing evidence to suggest that IR, a predecessor for both CAD and diabetes, is associated with chronic low-grade inflammation and oxidative stress [15]. There might be a continuous genesis of oxidative stress and inflammation in the natural history of diabetes with its perturbations starting as early as IGT $[16,17]$. Therefore, it is plausible to suggest that these factors could mechanistically connect insulin resistance and impaired glucose tolerance with changes in telomere length. This view is supported by our study in which telomere shortening in subjects with IGT was associated with insulin resistance, increased lipid peroxidation and protein carbonyl levels.

This study reconfirms our earlier work [3] that patients with Type 2 diabetes have telomere shortening. A recent study lends support to our observations that monocytes telomere lengths were significantly shorter in Type 2 diabetic subjects compared to control subjects [9]. While our studies (present and Ref. [3]) demonstrated an association of telomere shortening with systemic markers of oxidative stress (lipid peroxidation and protein oxidation) in Type 2 diabetes, the study by Sampson et al [9] also showed an association of telomere shortening and oxidative DNA damage. However, unlike our study, the telomere shortening observed by the European group was independent of glycemic control, IR and inflammatory markers [9]. The strong association of telomere shortening and IR shown in our study could imply a role of ethnicity as Indians have been shown to be more insulin resistant compared to their European counterparts [8].

Another important observation in this study is that telomere length was shorter in diabetic subjects with atherosclerotic plaques compared to their counterparts without plaques. Several studies have proposed that telomere shortening is a marker of biological ageing and atherosclerosis [18-20]. Benetos et al [1] have showed that shorter telomere was a significant predictor of the presence of carotid artery plaques in hypertensive subjects. Increased telomere shortening and IMT in diabetic patients with atherosclerotic plaques in our study clearly indicate a role for vascular senescence. Shorter telomeres have been demonstrated in coronary endothelial cells of patients with coronary heart disease [2] and, degen- 
erative aortic valve stenosis was also shown associated with shorter telomere length in the elderly [21]. Senescence in vascular smooth muscle cells (VSMCs) in atherosclerotic plaques was recently shown related to telomere shortening [22] and combining an in vitro work, this study concluded that human atherosclerosis was characterized by senescence of VSMCs, accelerated oxidative DNA damage, inhibition of telomerase and marked telomere shortening. A Japanese study also demonstrated that telomere shortening could be involved in the development of atherosclerotic disease in patients with hypercholesterolemia and diabetes [23]. Given that patients with high blood glucose are at an increased risk for cardiovascular disease, the results of our study suggest that in the presence of chronic hyperglycemia, shorter telomere in WBCs might serve as a biological indicator of increased predilection to carotid artery atherosclerosis.

While numerous studies have linked oxidative stress as a common denominator at the crossroad of insulin resistance, diabetes and cardiovascular diseases [7,16,24,25], oxidative stress is also considered as a common trigger for accelerated telomere shortening. The GGG-specific telomere sequence relative to rest of the chromosome has been shown highly susceptible to oxidative stress [26]. As we reported in this study, oxidative damage in macromolecules (lipid, protein, DNA) seen in various disease states correlates well with telomere shortening $[1,3,9,14]$. In our earlier study we showed that hsCRP has a strong association with diabetes and CAD [27]. The present work reveals an additional association between hs-CRP and telomere shortening in Type 2 diabetes. Since increased hs-CRP is a reflection of an inflammatory milieu and pro-oxidant effects of CRP are known [28], inflammation and oxidative stress might have synergistic effect on telomere shortening. Whatever may be the causes of telomere shortening, it would be important for the future studies to look for their impact on the regenerating and/or functional capacity of insulin-responsive tissues (pancreas, adipose and muscle). Indeed, premature telomere shortening and impaired regenerative response has been recently shown in hepatocytes of individuals with nonalcoholic fatty liver disease [29].

The positive association of HDL cholesterol and telomere length in our study also deserves special mention. It has been shown that increased HDL cholesterol and telomere length were linked to increased longevity in animal models and humans [30]. Low levels of HDL cholesterol are considered as one of the components of 'atherogenic dyslipidemia' [31] and low HDL cholesterol phenotypes have been recently shown to display elevated oxidative stress, attenuated antioxidative activity [32] and accelerated senescence [33].

In non-diabetic subjects, the age-adjusted telomere length is shorter in men than in women, confirming earlier studies $[3,34,35]$. This trend was persistently seen in subjects with IGT also, as reported in this study for the first time. As premenopausal women are less prone than men to cardiovascular diseases and several systemic parameters show poor correlation with blood pressure in women, our observa- tions suggest that the biology of ageing differs between men and women. We suggest that the enigmatic gender difference in telomere shortening and the natural history of diabetes need to be explored by longitudinal studies. Such studies are important because (a) estrogen is a potent anti-inflammatory and antioxidant agent; (b) there is an estrogen-response element present in hTERT [36]; (c) hormonal changes in women are expected to have drastic influences on insulin resistance, adiposity, oxidative stress and telomere length.

While Type 2 diabetes arise from the interaction of genetic predisposition and environmental factors, telomere length appears to be a reliable biomarker as it too influenced by genetic and environmental triggers. As telomere length is also highly heritable [37], probably X-linked in some cases [35], paternally inherited [38], mapped to a major locus on chromosome 12 [39] and considered as quantitative trait [40], the role of genetic predisposition to short telomeres in diabetes and associated disorders needs further investigations.

Being a cross-sectional one, our study cannot explain a cause and effect relationship of telomere shortening with diabetes development or progression to atherosclerosis. Assessing whether telomere erosion is an independent risk factor for IGT, Type 2 diabetes or proneness to atherosclerosis among diabetic subjects would require prospective studies. Nevertheless, because telomere shortening appears as a longterm biomarker, it would be interesting to see whether tight control of diabetes could halt or minimize this process.

In conclusion, our study shows that telomere shortening occurs in subjects with IGT (pre-diabetes) and is progressively greater in subjects with Type 2 diabetes and those with diabetes and atherosclerosis. As more data accumulates regarding telomere dynamics in the regulation of cell cycle events and cellular dysfunction in insulin-responsive target tissues, therapeutic opportunities may develop to prevent telomere shortening.

\section{Acknowledgments}

This work was supported by research grants (Dr. M. Balasubramanyam) from the Department of Science and Technology (DST \& DST-FIST), Govt. of India, New Delhi, India. Senior Research Fellowship (SRF) to Mrs. A. Adaikala Koteswari from the Council of Scientific \& Industrial Research (CSIR), New Delhi is also acknowledged. This is paper no. 39 from the Chennai Urban Rural Epidemiology Study (CURES).

\section{References}

[1] Benetos A, Gardner JP, Zureik M, et al. Short telomeres are associated with increased carotid atherosclerosis in hypertensive subjects. Hypertension 2004;43:182-5.

[2] Ogami M, Ikura Y, Ohsawa M, et al. Telomere shortening in human coronary artery diseases. Arterioscler Thromb Vasc Biol 2004;24: $546-50$. 
[3] Adaikalakoteswari A, Balasubramanyam M, Mohan V. Telomere shortening occurs in Asian Indian Type 2 diabetic patients. Diabetic Med 2005;22:1151-6.

[4] Mohan V, Gokulakrishnan K, Sandeep S, et al. Carotid intimal medial thickness, glucose intolerance and metabolic syndrome in Asian Indians - the Chennai Urban Rural Epidemiology Study (CURES-22). Diabetic Med 2006;3:845-50.

[5] Deepa M, Pradeepa R, Rema M, et al. The Chennai Urban Rural Epidemiology Study (CURES) - study design and methodology (urban component) (CURES-I). J Assoc Physicians India 2003;51:863-70.

[6] Mohan V, Ravikumar R, ShanthiRani S, Deepa R. Intimal medial thickness of the carotid artery in South Indian diabetic and nondiabetic subjects: the Chennai Urban Population Study (CUPS). Diabetologia 1998;433:494-9.

[7] Adaikalakoteswari A, Balasubramanyam M, Rema M, Mohan V. Differential gene expression of nadph oxidase (P22 $\left.{ }^{\text {phox }}\right)$ and hemoxygenase- 1 in patients with Type 2 Diabetes and microangiopathy. Diabetic Med 2006;23:666-74.

[8] Sharp PS, Mohan V, Levy JC, Mather HM, Kohner EM. Insulin resistance in patients of Asian Indian and European origin with non-insulin dependent diabetes. Horm Metab Res 1987;19:84-5.

[9] Sampson MJ, Winterbone MS, Hughes JC, Dozio N, Hughes DA. Monocyte telomere shortening and oxidative DNA damage in Type 2 diabetes. Diabetes Care 2006;29:283-9.

[10] Mohan V, Shanthirani CS, Deepa R. Glucose intolerance (diabetes and IGT) in a selected South Indian population with special reference to family history, obesity and lifestyle factors - the Chennai Urban Population Study (CUPS 14). J Assoc Physicians India 2003;51:771-7.

[11] Brouilette S, Singh RK, Thompson JR, Goodall AH, Samani NJ. White cell telomere length and risk of premature myocardial infarction. Arterioscler Thromb Vasc Biol 2003;23:842-6.

[12] Gardner JP, Li S, Srinivasan SR, et al. Rise in insulin resistance is associated with escalated telomere attrition. Circulation 2005;111:2171-7.

[13] Aviv A, Valdes A, Gardner JP, et al. Menopause modifies the association of leukocyte telomere length with insulin resistance and inflammation. J Clin Endocrinol Metab 2006;91:635-40.

[14] Demissie S, Levy D, Benjamin EJ, et al. Insulin resistance, oxidative stress, hypertension, and leukocyte telomere length in men from the Framingham Heart Study. Aging Cell 2006;5:325-30.

[15] Festa A, D'Agostino Jr R, Howard G, et al. Chronic subclinical inflammation as part of the insulin resistance syndrome: the Insulin Resistance Atherosclerosis Study (IRAS). Circulation 2000;102:42-7.

[16] Balasubramanyam M, Koteswari A, Samapthkumar R, Premanand C, Mohan V. Screening for oxidative stress in the general population: increased lipid peroxidation in the natural history of diabetes. Diab Metab 2003;29:4S167.

[17] Menon V, Ram M, Dorn J, et al. Oxidative stress and glucose levels in a population-based sample. Diabetic Med 2004;21:1346-52.

[18] Samani NJ, Boultby R, Butler RB, Thompson JR, Goodall AH. Telomere shortening in atherosclerosis. Lancet 2001;358:472-3.

[19] Minamino T, Miyauchi H, Yoshida T, et al. Endothelial cell senescence in human atherosclerosis: role of telomere in endothelial dysfunction. Circulation 2002;105:1541-4.

[20] Balasubramanyam M, Adaikalakoteswari A, Mohan V. Telomere shortening: a marker of atherosclerosis? Curr Sci 2004;87:422-4.

[21] Kurz DJ, Kloeckener-Gruissem B, Akhmedov A, et al. Degenerative aortic valve stenosis, but not coronary disease, is associated with shorter telomere length in the elderly. Arterioscler Thromb Vasc Biol 2006;26:e114-7.

[22] Matthews C, Gorenne I, Scott S, et al. Vascular smooth muscle cells undergo telomere-based senescence in human atherosclerosis: effects of telomerase and oxidative stress. Circ Res 2006;99:156-64.

[23] Obana N, Takagi S, Kinouchi Y, et al. Telomere shortening of peripheral blood mononuclear cells in coronary disease patients with metabolic disorders. Intern Med 2003;42:150-3.

[24] Ceriello A, Motz E. Is oxidative stress the pathogenic mechanism underlying insulin resistance, diabetes, and cardiovascular disease? The common soil hypothesis revisited. Arterioscler Thromb Vasc Biol 2004;24:816-23.

[25] Sampathkumar R, Balasubramanyam M, Sudarslal S, et al. Increased glutathionylated hemoglobin (HbSSG) in Type 2 diabetes subjects with microangiopathy. Clin Biochem 2005;38:892-9.

[26] Kawanishi S, Oikawa S. Mechanism of telomere shortening by oxidative stress. Ann N Y Acad Sci 2004;1019:278-84.

[27] Mohan V, Deepa R, Velmurugan K, Premalatha G. Association of Creactive protein with body fat, diabetes and coronary artery disease in Asian Indians: the Chennai Urban Rural Epidemiology Study (CURES6). Diabetic Med 2005;22:863-70.

[28] Fichtlscherer S, Breuer S, Schachinger V, Dimmeler S, Zeiher AM. Creactive protein levels determine systemic nitric oxide bioavailability in patients with coronary artery disease. Eur Heart J 2005;25:1412-8.

[29] Nakajima T, Moriguchi M, Katagishi T, et al. Premature telomere shortening and impaired regenerative response in hepatocytes of individuals with NAFLD. Liver Int 2006;26:23-31.

[30] Joeng KS, Song EJ, Lee KJ, Lee J. Long lifespan in worms with long telomeric DNA. Nat Genet 2004;36:607-11.

[31] Misra A, Luthra K, Vikram NK. Dyslipidemia in Asian Indians: determinants and significance. J Assoc Physicians India 2004;52:137-42.

[32] Kontush A, de Faria EC, Chantepie S, Chapman MJ. A normotriglyceridemic, low HDL-cholesterol phenotype is characterised by elevated oxidative stress and HDL particles with attenuated antioxidative activity. Atherosclerosis 2005;182:277-85.

[33] Nofer J, Walter M, Assmann G. Current understanding of the role of high-density lipoproteins in atherosclerosis and senescence. Exp Rev Cardiovasc Ther 2005;3:1071-86.

[34] Benetos A, Okuda K, Lajemi M, et al. Telomere length as an indicator of biologic aging: the gender effect and relation with pulse pressure and pulse wave velocity. Hypertension 2001;37:381-5.

[35] Nawrot TS, Staessen JA, Gardner JP, Aviv A. Telomere length and possible link to X chromosome. Lancet 2004;363:507-10.

[36] Kyo S, Takakura M, Kanaya T. Estrogen activates telomerase. Cancer Res 1999;59:5917-21.

[37] Slagboom PE, Droog S, Boomsma DI. Genetic determination of telomere size in humans: a twin study of three age groups. Am J Hum Genet 1994;55:876-82.

[38] Nordfjall K, Larefalk A, Lindgren P, Holmberg D, Roos G. Telomere length and heredity: indications of paternal inheritance. Proc Natl Acad Sci USA 2005;102:16374-8.

[39] Vasa-Nicotera M, Brouilette S, Mangino M, et al. Mapping of a major locus that determines telomere length in humans. Am J Hum Genet 2005;76:147-51.

[40] Gatbonton T, Imbesi M, Nelson M, et al. Telomere length as a quantitative trait: genome-wide survey and genetic mapping of telomere length control genes in yeast. PLoS Genet 2006;2(3):e35. 